University of Nebraska - Lincoln

DigitalCommons@University of Nebraska - Lincoln

3-1-1981

\title{
Magnetic properties of rare earth-gallium-iron glasses
}

S.G. Cornelison

University of Nebraska - Lincoln

David J. Sellmyer

University of Nebraska-Lincoln, dsellmyer@unl.edu

George C. Hadjipanayis

University of Nebraska-Lincoln, hadji@udel.edu

Follow this and additional works at: https://digitalcommons.unl.edu/physicssellmyer

Part of the Physics Commons

Cornelison, S.G.; Sellmyer, David J.; and Hadjipanayis, George C., "Magnetic properties of rare earthgallium-iron glasses" (1981). David Sellmyer Publications. 163.

https://digitalcommons.unl.edu/physicssellmyer/163

This Article is brought to you for free and open access by the Research Papers in Physics and Astronomy at DigitalCommons@University of Nebraska - Lincoln. It has been accepted for inclusion in David Sellmyer Publications by an authorized administrator of DigitalCommons@University of Nebraska - Lincoln. 


\title{
Magnetic properties of rare earth-gallium-iron glasses*
}

\author{
S. G. Cornelison, D. J. Sellmyer, and G. Hadjipanayis ${ }^{\dagger}$ \\ Behlen Laboratory of Physics, University of Nebraska, Lincoln, Nebraska 68588
}

\begin{abstract}
Results of magnetic susceptibility, high-field magnetization, and Mössbauer effect are reported for several R$\mathrm{Ga}$ and $\mathrm{R}-\mathrm{Ga}-\mathrm{Fe}$ metallic glasses, where $\mathrm{R}=\mathrm{Pr}$ and $\mathrm{Tb}$. Magnetic ordering temperatures, effective moments, and coercive forces were determined. In certain cases the data indicate that the low temperature states of magnetic order are asperomagnetic or spin-glass-like. For $\left(\mathrm{Pr}_{30} \mathrm{Ga}_{20}\right)_{80} \mathrm{Fe}_{20}$, several anomalies were observed including a large coercive field $(45 \mathrm{kOe})$ at $100 \mathrm{~K}$.
\end{abstract}

PACS numbers: $75.50 . \mathrm{Kj}, 75.30 . \mathrm{Cr}, 75.60 . \mathrm{Ej}$

\section{INTRODUCTION}

In our recent studies of rare-earth based metallic glasses we have reported unusual magnetic and electronic properties. [1-4]. Several theories have been proposed to explain the complex magnetic behavior which is often observed in rare-earth glasses. The local random anisotropy (LRA) model of Harris et al. [5] postulated the existence of relatively large, randomly oriented electric fields at the magnetic ion sites. This effect tends to scatter the magnetic moments away from the directions dictated by the local exchange fields. The dispersion of the moments in the magnetically ordered state leads to a lack of saturation of the high-field magnetization. Because of the random nature of amorphous alloys it is necessary to consider also fluctuations in the moments on the transition-metal ions [2] and fluctuations in the exchange couplings which lead to spin-glass like states. Our previous work has been concerned with alloys of nominal composition $R_{65}{ }^{\top} 35$, where $R$ denotes rare earth and $T$ denotes transition metal. In the present work we have studied rare-earth glasses of the form $\left(R_{80} G^{G 0}\right)_{100-x}{ }^{\top}$. These systems permit the systematic study of a new series of glasses ( $R-G a)$, and also al low us to investigate magnetic properties of glasses possibly containing a mixture of two amorphous phases ( $R-G a$ and $R-T$ ). We have made measurements on several rare-earth systems including $\mathrm{R}=\mathrm{La}, \mathrm{Pr}, \mathrm{Nd}, \mathrm{Gd}, \mathrm{Tb} ; \mathrm{T}=\mathrm{Fe}$ or $\mathrm{Co}$; and

$0 \leq x<30$. In this paper we will report only on the $\mathrm{Tb}^{-}$and $\mathrm{Pr}$ systems with $\mathrm{Fe}$, for $\mathrm{x}=0$ or 20 . We will discuss the magnetic properties as observed in highfield magnetization, susceptibility, and Mössbauer measurements.

\section{EXPERIMENTAL}

The samples were prepared from pure constituents by the splat-cooling technique. X-ray diffraction measurements were performed which yielded good liquidlike patterns on all the alloys; it was necessary to add $10 \%$ boron to the $\mathrm{Tb}_{80} \mathrm{Ga}_{20}$ alloy to stabilize the

glass. The susceptibility data were taken between 4.2 and $300 \mathrm{~K}$ at a field of $700 \mathrm{0e}$. A Faraday balance was used in conjunction with a microprocessor-based data-acquisition system. High-field magnetization data were taken using a vibrating sample magnetometer with fields up to $80 \mathrm{kOe}$, between $1.2 \mathrm{~K}$ and $250 \mathrm{~K}$. Mössbauer data were taken using a microprocessorbased sinusoidal velocity spectrometer.

\section{RESULTS}

\section{Magnetic Susceptibility}

Results of Faraday susceptibility measurements for $\left(\mathrm{Tb}_{80} \mathrm{Ga}_{20}\right)_{80} \mathrm{Fe}_{20}$ are shown in Fig. 1. The filled circles are data with $H=700$ oe after cooling in zero field and then increasing $T$. The open circles are data taken after cooling from room temperature to $4.2 \mathrm{~K}$ in a 700 oe field. This sample shows a broad peak and field-cooling effects below the ordering temperature which is suggestive of a spin-glass like state [6]. In the Tb-Ga-B sample the data in the fieldcooled state meet the data in the zero field cooled state close to the $53 \mathrm{~K}$ peak; however in the Tb-Ga-Fe sample the spin-freezing process apparently begins at about $125 \mathrm{~K}$ while the peak occurs at $88 \mathrm{~K}$. The paramagnetic susceptibility data for both alloys were fitted to the Curie-Weiss relation

$$
x=N \bar{p}^{-2} \mu_{B}^{2}\left[3 k_{B}(T-\theta)\right]^{-1}
$$

where $N$ is the number of magnetic ions per unit mass of alloy, $\bar{p}$ is the average paramagnetic moment per magnetic ion, and $\theta$ is the Weiss temperature. For the $\left(\mathrm{Tb}_{80} \mathrm{Ga}_{20}\right)_{90} \mathrm{~B}_{10}$ glass the fit gave $\theta=82 \mathrm{~K}$ and

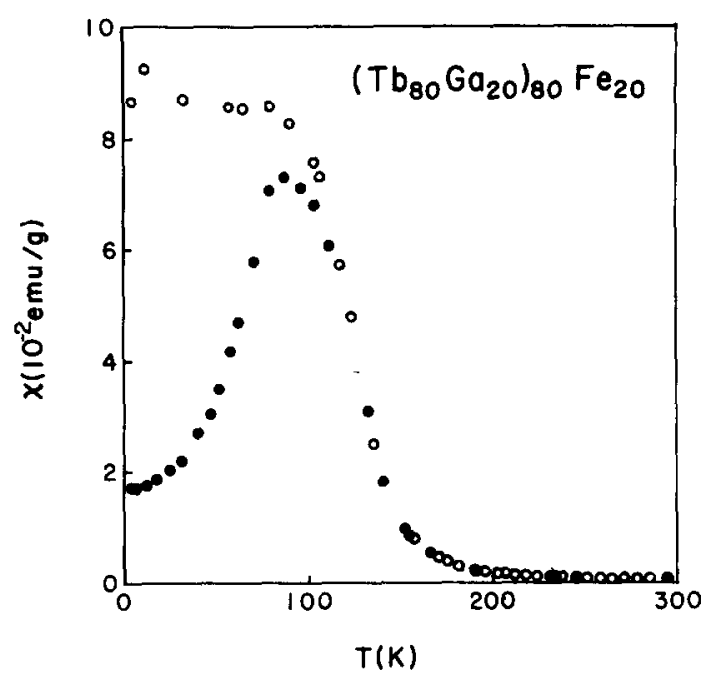

Fig. 1 Susceptibility of amorphous ( $\left.\mathrm{Tb}_{80} \mathrm{Ga}_{20}\right)_{80} \mathrm{Fe}_{20}$. Open circles are data taken after cooling in $700 \mathrm{Oe}$ and the solid circles represent data taken after cooling in zero field.

$\bar{p}=10.4$, the latter value being somewhat larger than that expected for free $\mathrm{Tb}^{3+}$ ions (9.72). The fit for for the Tb-Ga-Fe sample gave $\theta=167 \mathrm{~K}$ and $\overline{\mathrm{p}}=8.45$. Since there are two possible sources of local moments in this alloy ( $\mathrm{Tb}$ and $\mathrm{Fe}$ ), and since the $\mathrm{Tb}$ moment and 
concentration are much larger than those for $\mathrm{Fe}$, it is not possible to determine accurately a paramagnetic moment for the $\mathrm{Fe}$ ions in this glass.

Susceptibility data for $\operatorname{Pr}_{80} \mathrm{Ga}_{20}$ show a peak at

$7.0 \mathrm{~K}$. The Curie-Weiss fit gave $\theta=6.5 \mathrm{~K}$ and $\overline{\mathrm{p}}=$

3.37, which is not far from the free $\mathrm{Pr}^{+3}$ value of

3.58 .

Figure 2 shows the $X(T)$ data for the $\mathrm{Pr}-\mathrm{Ga}-\mathrm{Fe}$ glass. Open circles are data taken after cooling in $700 \mathrm{Oe}$ and the solid circles represent data taken after cooling in zero field. Apparently a second peak is being approached as $T$ increases above room temperature.

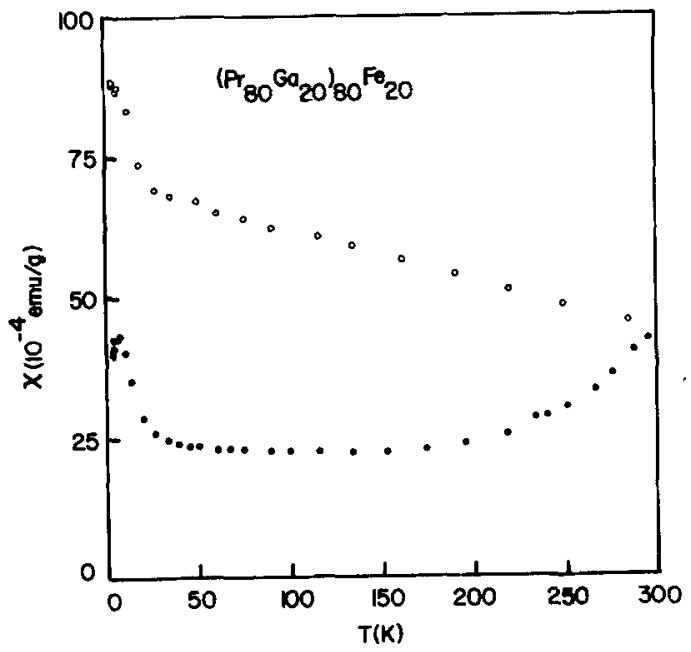

Fig. 2. Susceptibility of amorphous $\left(\operatorname{Pr}_{80} \mathrm{Ga}_{20}\right)_{80} \mathrm{Fe}_{20}$. Open circles are data taken after cooling in $7000 \mathrm{e}$ and the solid circles represent data taken after cooling in zero field.

\section{Magnetization}

Magnetization data to $80 \mathrm{k}$ e were obtained on all the samples from $4.2 \mathrm{~K}$ to $250 \mathrm{~K}$. Data on the Tb-Ga-B glass show a coercivity $\mathrm{H}_{\mathrm{C}}$ of $23.6 \mathrm{kOe}$ at $4.2 \mathrm{~K}$ and an extrapolation from high-fields to $H=0$ gives a 'spontaneous' magnetization $\left(\mu_{0}\right)$ of $124.5 \mathrm{emu} / \mathrm{gram}$.

The coercivity of this sample decreases sharply with increasing temperature and disappears entirely at about $25 \mathrm{~K}$. Relatively large curvature of the magnetization data at $80 \mathrm{kOe}$ was observed at all temperatures studied. Data for the Tb-Ga-Fe are shown in Figure 3. The data display non saturation at high fields and a large coercivity of $31.6 \mathrm{kOe}$ is observed in the $4.2 \mathrm{~K}$ loop. A spontaneous moment of $152 \mathrm{emu} /$ gram is obtained from the $4.2 \mathrm{~K}$ data. The coercivity monotonically decreases with increasing $T$ and disappears at about $75 \mathrm{~K}$.

Magnetization data of $\mathrm{Pr}_{80} \mathrm{Ga}_{20}$ exhibit a small coercivity at $4.2 \mathrm{~K}$ and none above that temperature. A spontaneous magnetization of $26.3 \mathrm{emu} / \mathrm{gram}$ is estimated but the large curvature in the magnetization high fields make this value uncertain.

Figure 4 shows some magnetization loops for $\left(\mathrm{Pr}_{80} \mathrm{Ga}_{20}\right)_{80} \mathrm{Fe}_{20}$. The $4.2 \mathrm{~K}$ loop is displaced slightly upwards and shows an asymmetric coercivity of $2150 \mathrm{0e}$. A spontaneous magnetization of $21.5 \mathrm{emu} /$ gram is obtained by the standard technique. An interesting feature of this alloy is that the coercivity increases as the temperature increases. A peak of about $45 \mathrm{kOe}$ in the coercivity is observed at $\mathrm{T}=100 \mathrm{~K}$. Then the coercivity decreases monotonically to a small but non-zero value at room temperature. Also associ- ated with this are upward shifts of the loops of up to over $10 \mathrm{emu} / \mathrm{gram}$ in field cooled specimens and the appearance of hysteresis in the high-field portion of higher-temperature data.

\section{Mössbatuer Effect}

Fig. 5 shows ${ }^{57} \mathrm{Fe}$ Mössbauer data which were taken at room temperature on $\left(\mathrm{Pr}_{80} \mathrm{Ga}_{20}\right)_{80} \mathrm{Fe}_{20}$ which had been appropriately enriched with ${ }^{57} \mathrm{Fe}$. All the data at different temperatures exhibit a six-line spectrum which shows little change as $T$ is lowered to $4.2 \mathrm{~K}$. The data suggest a moment of about $1.4 \mu_{B}$ per iron atom. These data also are direct evidence that precipitation of the Laves phase $\mathrm{PrFe}_{2}$ is not a large factor since data by Shimotomai et al. [7] indicate an internal field of $160 \mathrm{kOe}$ compared to the measured $210 \mathrm{kOe}$ for this data. Similarly $\alpha-\mathrm{Fe}$ is not the source of the major Mössbauer lines because the hyperfine field for pure $\mathrm{Fe}$ is $330 \mathrm{kOe}$. Thus far internal field deconvolutions have not been performed to obtain further information on local environments of the $\mathrm{Fe}$ atoms in this glass.

\section{DISCUSSION}

\section{Terbium-Based Glasses}

The spontaneous magnetization $\left(\mu_{0}\right)$ observed for Tb-Ga-B corresponds to $0.44 \mathrm{gJ} \mu_{B}$ per Tb ion which is smaller than $0.5 \mathrm{gJ} \mu_{B}$ per Tb expected for a hemispherical fan of spins. The positive $\theta$ value of $82 \mathrm{~K}$ indicates predominantly ferromagnetic exchange interactions. These facts together suggest that the ordered magnetic structure is approximately asperomagnetic, that is, the moments are scattered into a hemispherical "fan." [8] The asperomagnet ic ordering, large lowtemperature coercivity, and high-field magnetization all are consistent with the presence of large LRA in this giass.

The effect of adding $F e$ to $T b-G a$ is to increase $\theta$ to $167 \mathrm{~K}$, increase the coercivity to $31.6 \mathrm{kOe}$, and to increase the spontaneous magnetization. Thus the net or average exchange seems to increase despite the expected antiparallel coupling of the $\mathrm{Tb}$ and $\mathrm{Fe}$ moments. The Fe also hardens the magnetic properties and the decay of the coercivity with temperature suggests a thermal activation of domains over energy barriers

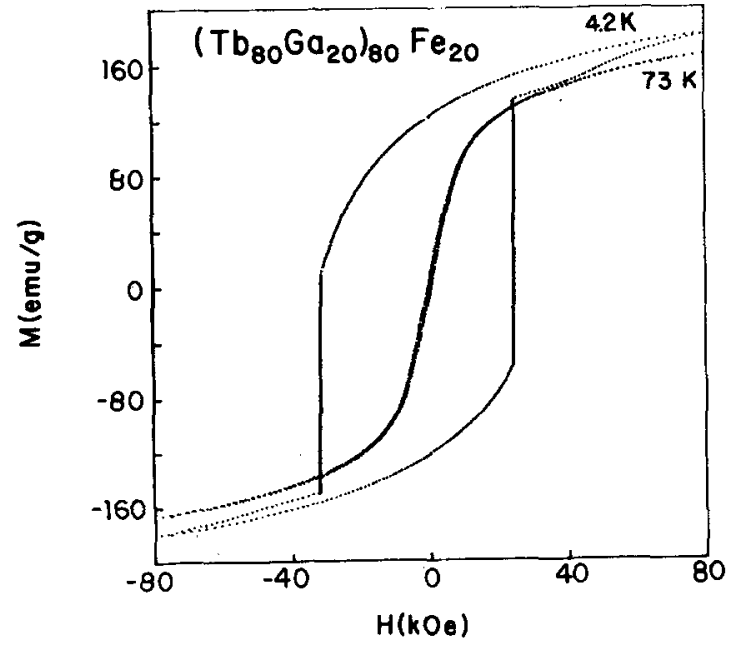

Fig. 3. Hysteresis loops at $4.2 \mathrm{~K}$ and $73 \mathrm{~K}$ for amorphous ( $\left.\mathrm{Tb}_{80} \mathrm{Ga}_{20}\right)_{80} \mathrm{Fe}_{20}$. 
as suggested previously for $\mathrm{Tb}_{75} \mathrm{Au}_{25}[3]$.

\section{Praseodymium Based Glasses}

The positive $\theta$ value for $\operatorname{Pr}_{80} G^{G} a_{20}$ indicates a ferromagnetic exchange interaction. The spontaneous magnetization corresponds to a value of only about $0.2 \mathrm{gJH}_{\mathrm{B}}$ per $\mathrm{Pr}$ ion, despite the fact that in the paramagnetic state the effective moment value measured is rather close to that expected for free $\mathrm{Pr}^{3+}$ ions. This situation is in contrast to the similar glass,

( $\left.\operatorname{Pr}_{80} \mathrm{Au}_{20}\right)_{90^{B}}{ }_{10}$, in which both the effective moment and the spontaneous moment were reduced from those expected for free $\mathrm{Pr}^{3+}$ ions ordering into an asperomagnetic state [3]. In the latter case the data are consistent with moments, reduced by 'crystal-field' effects, which however, still order asperomagnetically. The present data on $\mathrm{Pr}-\mathrm{Ga}$ suggest that the magnetic order in this case is more spin-glass like in character. That is, the half-angle of the asperomagnetic cone has become larger than $90^{\circ}$. This might be evidence for the most recent theoretical predictions that the ground state of the LRA Hamiltonian for positive exchange is a spinglass-like rather than asperomagnetic state. [9]

The addition of $\mathrm{Fe}$ to $\mathrm{Pr}-\mathrm{Ga}$ leads to complex but interesting behavior. The data suggest the presence of a second magnetic transition above room temperature in addition to the low temperature one based predominantly on $\mathrm{Pr}-\mathrm{Ga}$. The most interesting aspect of the $\mathrm{Pr}-\mathrm{Ga}-\mathrm{Fe}$ glass is the increase of the coercivity to the large value of $45 \mathrm{kOe}$ at the relatively high temperature of $100 \mathrm{~K}$. The coercivity falls to smaller values at both $4.2 \mathrm{~K}$ and $300 \mathrm{~K}$. Associated with the anomalies at about $100 \mathrm{~K}$ are upward shifts of the hysteres is loops and the opening up of the hysteres is loops at high fields. These phenomena may be related to the presence of exchange anisotropy such as that observed in canonical spin-glasses such as $\mathrm{Cu}(\mathrm{Mn})$. Similar effects have been observed in metallic glasses.

Because of the presence of two magnetic species in $\mathrm{Pr}-\mathrm{Ga}-\mathrm{Fe}$, one might expect that there would be large fluctuations in the exchange fields. It may be possible that the anomalously large coercivity could result from such fluctuations as suggested by ostereicher $[10]$.

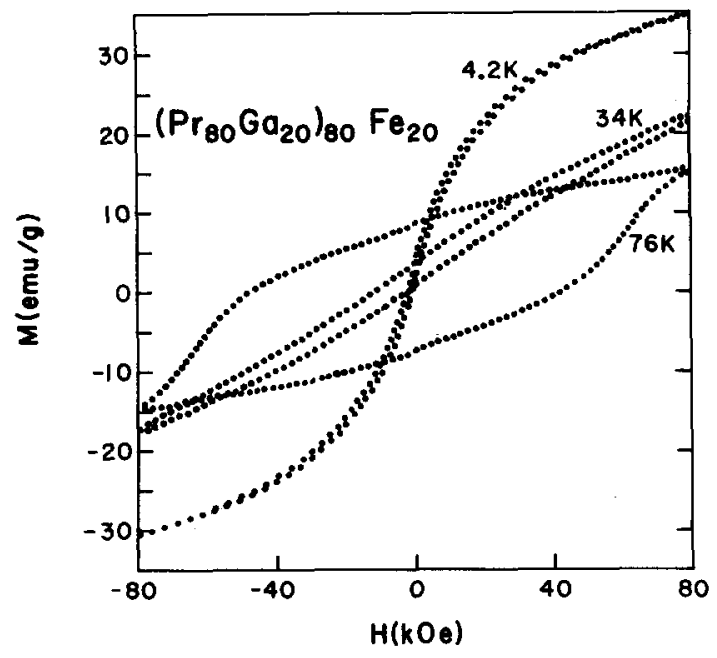

Fig. 4. Hysteresis loops at $4.2 \mathrm{~K}, 34 \mathrm{~K}$ and $76 \mathrm{~K}$

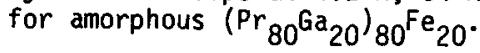

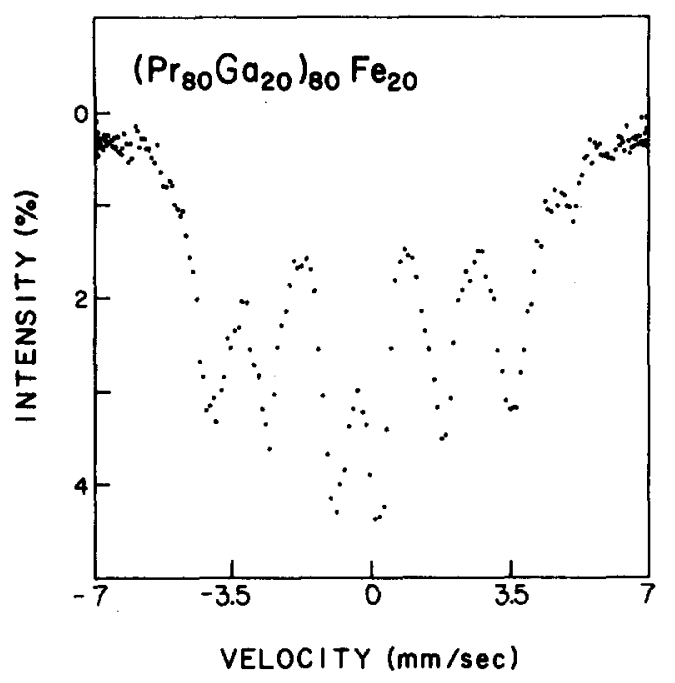

Fig. 5. Room temperature ${ }^{57} \mathrm{Fe}$ Mössbauer spectrum of amorphous $\left(\mathrm{Pr}_{80} \mathrm{Ga}_{20}\right)_{80} \mathrm{Fe}_{20}$.

In a phenomenological sense, certain aspects of the data can be understood on the basis of two coupled magnetic subnetworks. Recent work of Buschow and van Engen [11] on $\mathrm{Pr}_{1-x} \mathrm{Fe}_{x}$ glasses also indicates some high temperature anomalies. Thus our high temperature ordering in $\mathrm{Pr}-\mathrm{Ga}-\mathrm{Fe}$ may involve an amorphous $\mathrm{Pr}-\mathrm{Fe}$ structure embedded in some sense in a glassy $\mathrm{Pr}-\mathrm{Ga}$ matrix. The evidence does not indicate the presence of gross precipitation into a two phase system. Clearly, however, additional information is needed on the short range atomic correlations and clusters, before a detailed understanding of the anomalies can be achieved.

\section{REFERENCES}

* Research supported by NSF Grant DMR 7810781.

Present address: Inland Research and Development Center, Radford, VA 24141

1. J.A. Gerber, D.J. Miller and D.J. Sellmyer, J. App 1. Phys. 49, 1699 (1978).

2. J.A. Gerber, S.G. Cornelison, W.L. Burmester and D.J. Sellmyer, J. App 1. Phys. 50, 1608 (1979).

3. D.J. Sellmyer, G. Hadjipanayis and S.G. Cornelison, J. Non-Crystalline Solids 40,437 (1980).

4. G. Hadjipanayis, S.G. Cornelison, J.A. Gerber and D.J. Sellmyer, J. Mag. Magn. Mat. 21, 101 (1980).

5. R. Harris, M. Plischke and M.J. Zuckerman, Phys. Rev. Letters 31, 160 (1973); R.W. Cochrane, R. Harris and M.J. Zuckerman, Phys. Rep. 48, 1 (1978).

6. J.A. Mydosh, AIP Conf. Proc. 24, 131 (1975).

7. M. Shimotomai, H. Miyake and M. Doyama, J. Phys. F: Metal Phys., 10, 707 (1980).

8. J.M.D. Coey, J. App i. Phys. 49, 1646 (1978).

9. See Jayaprakash and S. Kirkpatrick, Phys. Rev. B 21,4072 (1980), and references therein.

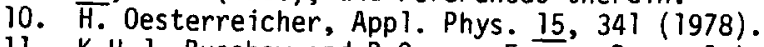

11. K.H.J. Buschow and P.G. van Engen, Proc. Int. Conf. Liquid and Amorphous Metals, Grenoble, (1980) (in press). 